\title{
Participação política e gestão urbana sob o Estatuto da Cidade'
}

\author{
Political participation and urban management under the Statute of the City
}

Jefferson Oliveira Goulart ${ }^{[0, \text { b] }}$, Eliana Tadeu Terci[c] Estevam Vanale Otero ${ }^{[\mathrm{d}]}$

[a] Universidade Estadual Paulista (Unesp), Faculdade de Arquitetura, Artes e Comunicação (FAAC), Departamento de Ciências Humanas, Bauru, SP, Brasil

[b] Centro de Estudos de Cultura Contemporânea (CEDEC), São Paulo, SP, Brasil

[c] Universidade de São Paulo (USP), Escola Superior de Agricultura Luiz de Queiroz (ESALQ), Departamento de Economia, Administração e Sociologia, Piracicaba, SP, Brasil

[d] Universidade Metodista de Piracicaba (UNIMEP), Piracicaba, SP, Brasil

\section{Resumo}

A versão hegemônica da democracia tem inspiração na abordagem de Schumpeter, legado do pluralismo liberal que a reduz à formação de maiorias legítimas por meio da representação. Não obstante, a democratização de países que passaram pelo autoritarismo proporcionou experiências inovadoras da sociedade civil em novos formatos participativos. No Brasil, essa experimentação tem particular expressão em nível municipal. No plano institucional, o Estatuto da Cidade regulamentou o capítulo da Política Urbana da Constituição Federal de 1988 e preconiza formatos participativos de políticas públicas de gestão urbana "por meio da participação pública e as associações representativas". A construção dessa agenda resulta de imposição institucional e reflete decisões governamentais e demandas da sociedade civil. 0 texto analisa a participação, seu alcance para compartilhar decisões e em que medida esses formatos participativos dependem dos governos na implantação de novos paradigmas de gestão urbana. A abordagem combina análise teórica e empírica de processos de elaboração de Planos Diretores orientados normativamente pelo Estatuto da Cidade. A base empírica é formada por três cidades médias do interior paulista: Piracicaba, Bauru e Rio Claro.

Palavras-chave: Participação. Gestão Urbana. Estatuto da Cidade.

\begin{abstract}
1 Este artigo apresenta resultados preliminares de pesquisa financiada pela Fundação de Amparo à Pesquisa do Estado de São Paulo (Fapesp): Processos contemporâneos de desenvolvimento urbano em cidades médias: Estatuto da Cidade, expansão imobiliária, engrenagem econômica e dinâmica decisória político-institucional (2001-2011) (Processo 2011/14082-3), cuja versão original foi apresentada no Painel Nuevas demandas ciudadanas: instituciones democráticas a prueba?, no $22^{\text {nd }}$ World Congress of Political Science, realizado em Madri/Espanha, 2012.
\end{abstract}

JOG é Doutor em Ciência Política, e-mail: jgoulart@faac.unesp.br

ETT é Doutora em História, e-mail: etterci@usp.br

EVO é Mestre e doutorando em Arquitetura e Urbanismo, e-mail: estevamotero@yahoo.com

urbe. Revista Brasileira de Gestão Urbana (Brazilian Journal of Urban Management), 2015 jan./abr., 7(1), 122-135 
The hegemonic version of democracy is based on Schumpeter's approach, a legacy of liberal pluralism that reduces the formation of legitimate majorities through representation. Nevertheless, the democratization of authoritarian countries has provided innovative experiences of civil society in new participatory formats. At the institutional level, the Statute of the City regulated the chapter of the Urban Policy of the Federal Constitution of 1988. It advocates participatory formats of public policies in urban management "through public participation and representative associations". The construction of this agenda is the result of institutional imposition and it reflects the government decisions and civil society demands. This paper analyzes the participation, its ability to share decisions, and to what extent these participatory formats depend on governments for the implementation of new paradigms of urban management. The approach combines theoretical and empirical analysis of development processes of Master Plans normatively guided by the City Statute. The empirical basis is formed by three medium-sized cities in Sao Paulo state: Piracicaba, Bauru and Rio Claro.

Keywords: Participation. Urban Management. Statute of the City.

\section{Contexto histórico e referências teóricas}

0 tema dessa reflexão é o exame comparativo de experiências de Planos Diretores Participativos em três cidades médias do interior paulista: Piracicaba, Bauru e Rio Claro. Antes de uma apreciação sobre o formato e o desempenho desses arranjos e da institucionalização da participação, cumpre balizar os termos desse debate.

A participação integra a agenda da pesquisa acadêmica há tempos, e particularmente no Brasil ganhou relevância desde a década de 1970, período em que proliferaram movimentos sociais e no qual ganhou impulso a luta contra o regime autoritário. o campo analítico da democratização ampliouse porque esta não se limitou a uma mudança de regime político (de uma ditadura para uma democracia) e porque incorporou os movimentos societários que invadiram a cena política (Sader, 1988).

Da óptica dos movimentos sociais, a ambiguidade foi sintetizada na tensão entre duas concepções. De um lado, manifestava-se "a face integrativocorporativa, pela qual se buscava conquistar maiores níveis de integração social pelo acesso a bens e serviços" (Doimo, 1995, p. 69), posição mais negociadora e predisposta a se institucionalizar. De outra parte, vicejava a "face expressivo-disruptiva, pela qual se manifestam valores morais ou apelos ético-políticos tendentes a deslegitimar a autoridade política" (Doimo, 1995, p. 69), na qual podemos identificar um componente basista. ${ }^{2}$ Essa visão mais dura e refratária às instituições políticas ganhou interpretação como "visão basista que dilui os atores numa multiplicidade de cenários e agendas e acaba por fazer com que eles conquistem uma liberdade que não os leva a parte alguma" (Kowarick, 2000, p. 128).

Durante a década de 1970 operam basicamente três matrizes discursivas: a Teologia da Libertação (basista); a dos grupos de esquerda remanescentes da resistência armada (de múltiplas acepções marxistas); e a do novo sindicalismo (Sader, 1988). Não se trata de detalhar os fundamentos de cada uma, tampouco aclarar quais foram mais potentes, mas de registrar as raízes e contradições da emergência do tema da participação. Algumas dessas concepções também contaminaram seus intérpretes, como os que identificavam na sociedade civil a chave para a autonomia dos movimentos (teorias da nova sociedade civil), para os quais os movimentos sociais seriam portadores de uma imanente capacidade de universalização de direitos e não carregariam os vícios das instituições políticas tradicionais (parlamento, partidos, sistema representativo etc.).

\footnotetext{
${ }^{2}$ O basismo se distingue pela contestação da autoridade decisória das instituições do Estado e propõe a sistemática "consulta às bases" nos processos de tomada de decisões, pois considera que só estas têm legitimidade na escolha de políticas e de estratégias. Historicamente, no Brasil esteve mais fortemente associado aos movimentos articulados em torno da influência da Igreja Católica e da Teologia da Libertação, especialmente às Comunidades Eclesiais de Base (CEBs).
} 
Essa visão prosperou tanto porque absorveu a tendência à satanização do Estado e das instituições políticas quanto porque forjou certa idealização de que os novos formatos participativos seriam suficientemente democráticos a partir de uma nova sociedade civil. Essa visão atribuía peso excessivo ao potencial transformador dos atores sociais, postulando que estes seriam capazes de promover distribuição de bens materiais e imateriais e de democratizar os processos decisórios.

0 tempo e a história se encarregaram de dirimir quaisquer dúvidas sobre tais crenças, e a participação "atingiu patamares de institucionalização ímpares", ou seja: "não perdeu seu registro simbólico original, mas adquiriu novo registro dominante porque inserida nos chamados 'espaços participativos'. Os atores sociais inseriram-se nesses novos espaços e a literatura acadêmica migrou com eles" (Lavalle, 2011, p. 13-14). Em síntese, a participação se institucionalizou. Os formatos participativos contemporâneos passaram a interagir com as estruturas do Estado: absorvidos, regrados e normatizados, seus atores se integraram à formulação de políticas públicas.

0 ponto de partida da variedade de olhares sobre a democracia reside na crítica à concepção pluralista cuja matriz reside na obra de Schumpeter (1984), segundo a qual a democracia "se redefine simplesmente como uma maneira de gerar uma minoria governante legítima" (Miguel, 2005, p. 9). Assim, o que distingue a democracia é a regra tomada em dupla dimensão: primeiro, no sentido de que seja assegurada igual difusão de oportunidades para que todos os cidadãos possam manifestar suas preferências; segundo, que essa condição institucional esteja subordinada à prevalência da vontade da maioria, que, por sua vez, é representada por minorias legítimas. São as regras do jogo, predeterminadas por um contrato que tem a adesão prévia de todos que a elas se submetem.

A democracia de acepção pluralista postula uma forma (o método de tomada de decisões e a legitimidade de quem as toma em nome da maioria), não é definida pelo conteúdo (pelos resultados sociais ou morais) que possa produzir. Nessa acepção que se tornou hegemônica, a competição entre elites políticas admite papel limitado ao povo, que escolhe os que tomam decisões em seu nome: a democracia se reduziria à escolha de governantes, de modo que a ideia de cidadãos politicamente ativos, culturalmente educados e bem informados não encontraria correspondência na vida real - dominada por indivíduos apáticos e limitados à efetivação egoísta de seus próprios interesses.

Como expressão crítica das limitações da democracia liberal-pluralista, a participação (entendida como ampliação dos espaços decisórios) encontra amparo teórico em, pelo menos, duas correntes da teoria democrática: na democracia deliberativa e na democracia participativa.

No caso da concepção da democracia deliberativa, postulam-se mais debates sem posições predefinidas e se crê que demandas da sociedade civil são intrinsecamente benfazejas porque universalizariam direitos, bens e serviços - daí sua legitimidade e capacidade de promover justiça, valorizando a dimensão discursiva do processo decisório, isto é, a esfera comunicacional entre os diferentes atores políticos e sociais.

Essa visão é crítica da percepção liberal, atribuindo-lhe desprezo pelo princípio da autodeterminação. ${ }^{3}$ Sua perspectiva normativa reclama uma conceituação mais complexa da soberania popular como procedimento, de modo que as fontes do mundo da vida não só reduziriam as ações do aparelho estatal como produziriam uma cultura política libertária e uma socialização política esclarecida. Para Habermas (1997), pioneiro e principal pensador da democracia deliberativa, é fundamental que exista uma esfera pública como arena para o debate e a persuasão, não importando se as condições de igualdade para essas disputas sejam efetivas, ou seja, "a igualdade substantiva não é importante” (Miguel, 2005, p. 14). Em suma, privilegia-se a dimensão discursiva do debate público, na qual residiria a capacidade emancipatória dos sujeitos, posto que a regra da maioria seria mais complexa do que sugere a perspectiva pluralista, pois requer debate, persuasão e ação comunicativa. Assim, são rejeitadas as definições minimalistas (democracia meramente como método legítimo de

\footnotetext{
3 Trata-se de questão central na teoria política que emerge com a modernidade e diz respeito ao conceito de soberania. Habermas (1990) observa que a Revolução Francesa introduziu uma nova concepção de poder ao atribuir ao povo a prerrogativa soberana de se autogovernar. Tal entendimento já havia sido anunciado por J. J. Rousseau, cuja concepção do Contrato Social se distingue de outros autores da tradição jusnaturalista precisamente porque, ao opor a liberdade à servidão, remete à vontade geral a solução das desigualdades. Nesses termos, a autodeterminação é entendida como livre-arbítrio, ausência de tirania ou mesmo soberania política.
} 
escolha de governantes) e a percepção puramente procedimental da democracia representativa (Habermas, 1997).

No caso da democracia participativa, a aposta é que, face à limitação do sistema representativo, a participação per se implicaria a ampliação de espaços decisórios. Os adeptos da radicalização participativa têm em Pateman (1992) uma interlocutora privilegiada à medida que essa autora desenvolve uma crítica acentuada dos "limites" da democracia representativa: seu desacordo básico repousa na absolutização dos arranjos institucionais e em sua percepção (negativa) da participação, entendida meramente como proteção de interesses particularistas. Resgatando a ideia de vontade geral e contestando a concepção de democracia resumida ao método, Pateman (1992) advoga a participação em todos os níveis da vida social e política como melhor percurso do aprendizado democrático.

Essa concepção não assimila a apatia do cidadão comum, rejeita a falta de imaginação política e sociológica da teoria da democracia contemporânea e, quase romanticamente, relaciona de forma automática a intensificação da experiência participativa à redução das atitudes individuais não democráticas. Nada asseguraria, inversamente, que essa percepção pudesse ser mais bem apreendida nos moldes da representação.

0 problema desse tipo de prescrição reside na crença de que a generalização da participação traria consigo uma carga benévola de incentivos, ignorando os conflitos entre diferentes atores sociais e políticos. Mais: confere um papel subalterno às instituições da democracia representativa, supondo se tratarem de estruturas elitistas. Participação, nesses termos, assume uma dupla significação: tanto exprime tomar parte de processos decisórios que transcendem os mecanismos político-eleitorais, quanto representa partilha de bens e serviços que uma sociedade desigual (como a capitalista) tem enorme dificuldade em promover. Se, para os pluralistas, a democracia é forma antes de qualquer exigência, para os participacionistas, normativamente, também deve produzir um conteúdo: distributivo em termos de acesso a bens materiais; e equitativo em termos de pertencimento e integração aos foros decisórios.

A participação pode ser definida como "formas diferenciadas de incorporação de cidadãos e associações da sociedade civil na deliberação sobre políticas" (Avritzer, 2008, p. 45), permeada por interesses corporativos e particulares que refletem a multiplicidade das sociedades contemporâneas. Contemporaneamente, contudo, a participação deixou de ser estritamente uma expressão da sociedade civil para penetrar nas redes institucionais estatais e partilhar diferentes níveis de responsabilidades na formulação de políticas públicas. A participação se institucionalizou, foi absorvida pelo Estado e é por ele regrada em larga medida, constituindo uma esfera híbrida que toca e se confunde com a representação - descrição observada empiricamente nas políticas de desenvolvimento urbano e nos Planos Diretores Participativos.

A participação também pode ser tomada como "categoria nativa da prática política de atores sociais, categoria teórica da teoria democrática e procedimento institucionalizado com funções delimitadas por leis e disposições regimentais" (Lavalle \& Vera, 2011, p. 101). Para os propósitos dessa reflexão (incorporados os ideais de autodeterminação e de igualdade política que lhes são historicamente próprios), a participação será analisada sob a última dessas perspectivas, a saber, da institucionalização e do desempenho de um determinado arranjo participativo (Planos Diretores).

\section{Da participação ao Estatuto da Cidade}

Dentre os diversos movimentos sociais que invadiram a cena social e política desde a década de 1970, interessa destacar o da reforma urbana. As diferentes experiências de lutas e a agenda da democratização criaram as condições para formação do Foro Nacional da Reforma Urbana e do Movimento Nacional pela Reforma Urbana, integrados por movimentos populares (principalmente de habitação), associações de classe (arquitetos e engenheiros, sobretudo), organizações não governamentais (assessoria, formação etc.) e instituições de pesquisa (muitas vinculadas a universidades).

A agenda da reforma urbana se impôs pelo caráter excludente do desenvolvimento urbano. A literatura sociológica de orientação marxista absorveu esses temas e ganhou impulso com uma obra seminal, A espoliação urbana (Kowarick, 1993), na qual se identifica que a desordem urbana obedecia à lógica da acumulação predatória. 
O caos urbano é identificado pela generalização de habitações precárias (cortiços, favelas) e ganhou nova expressão na oposição centro-periferia - díade que sintetiza a segregação socioespacial que expulsa as camadas populares para periferias privadas de infraestrutura. Embora não tenham sido poucas as instituições e agências criadas nesse período - Sistema Financeiro de Habitação (SFH), Banco Nacional de Habitação (BNH), Serviço Federal de Habitação e Urbanismo (Serfhau), dentre outras -, a ação estatal não só não reverteu como intensificou a espoliação urbana. As políticas habitacionais não atenderam os estratos sociais mais necessitados e privilegiaram os segmentos médios e grandes obras de infraestrutura (Maricato, 1987); a proliferação de Planos Diretores não conseguiu ordenar e planejar o crescimento urbano (Villaça, 2004); e a evolução cortiço-favela-periferia manteve inalterada no essencial a percepção (e o tratamento) das elites sobre a pobreza urbana (Valladares, 1994).

Não obstante, não é recomendável homogeneizar o urbano: características como especulação imobiliária, segregação socioespacial e outras são comuns às cidades brasileiras, mas é preciso reconhecer diferenças como clivagens regionais, formatos político-institucionais, escalas demográficas, peso econômico, configuração social, especificidades territoriais, capacidade de polarização etc. (Spósito et al., 2006). A imprecisão analítica também foi motivada pela dinâmica federativa brasileira, cujo histórico é marcado por longos períodos de centralização que concentraram recursos de poder ao nível da União (prerrogativa decisória, orçamento etc.), com clara desvantagem para os níveis subnacionais. ${ }^{4}$

Embora no passado as políticas públicas tenham sido concentradas nos níveis superiores de governo (especialmente na esfera federal, casos emblemáticos do SFH e do BNH), legislações e políticas municipais foram determinantes para definir os contornos do território e do desenvolvimento urbano. Assim, o processo de urbanização se desenvolveu através de "gestões urbanas que têm uma tradição de investimento regressivo", de sorte que "as obras

\footnotetext{
4 Parte dessa assimetria foi atenuada com a Constituição de 1988, seja pela (circunstancial) elevação das receitas dos níveis de governo subnacionais, seja pela (estrutural) mudança de status que resultou no reconhecimento dos municípios como entes federados dotados de autonomia.
}

de infraestrutura urbana alimentam a especulação fundiária e não a democratização do acesso à terra para moradia" (Maricato, 2000, p. 157).

A mais importante ação institucional na agenda da reforma urbana veio com o processo constituinte de 1986-88, que absorveu a demanda da participação e a agenda democrática. Ademais, seu regimento também acolheu o instituto da emenda popular, através do qual a iniciativa legislativa poderia ser patrocinada por entidades civis, possibilidade que culminou com o encaminhamento de 11.989 sugestões no período inicial dos trabalhos (Michiles et al., 1989).

Assim, a reforma urbana foi objeto de emenda de iniciativa popular patrocinada pela Federação Nacional dos Engenheiros, Federação Nacional dos Arquitetos e Instituto de Arquitetos do Brasil, com 133.068 assinaturas. Pela primeira vez uma Constituição trazia um capítulo específico dedicado à questão urbana, com ampla inovação: além do usucapião urbana (Brasil, 1996, Art. 183), o direito de propriedade foi subordinado à sua função social, invertendo alicerce fundamental de uma sociedade capitalista (Brasil, 1996, Art. 182).

Após treze anos de intensas disputas, os enunciados da Constituição foram regulamentados através de legislação infraconstitucional e ganharam forma no Estatuto da Cidade - Lei Federal n. 10.257/2001 (Brasil, 2002) -, o qual preconiza formatos participativos de formulação e implantação de políticas públicas (Planos Diretores Participativos, audiências públicas, conselhos etc.).

A participação foi consagrada como princípio mediante "gestãodemocrática pormeioda participação da população e de associações representativas dos vários segmentos da comunidade na formulação, execução e acompanhamento de planos, programas e projetos de desenvolvimento urbano" (Brasil, 2002, Art. $\left.2^{\mathrm{o}}\right) .{ }^{5}$ Assim, a agenda da participação no arranjo institucional do desenvolvimento urbano ganhou materialidade na aplicação do Estatuto da Cidade por meio dos Planos Diretores.

\footnotetext{
${ }^{5}$ Embora não integre o escopo dessa reflexão, o EC também se notabilizou por um variado elenco de instrumentos urbanísticos transformadores orientados para conter a especulação imobiliária e promover a democratização do acesso à cidade, dentre os quais merecem destaque: a Outorga Onerosa do Direito de Construir, as Zonas Especiais de Interesse Social, o Imposto Predial e Territorial Urbano (IPTU) progressivo no tempo, o Direito de Preempção, o Estudo de Impacto de Vizinhança.
} 


\section{Os Planos Diretores Participativos}

O debate sobre a efetividade dos Planos Diretores é controverso na literatura urbanística, polêmica aquecida porque a proposta do Movimento Nacional pela Reforma Urbana não incluía sua exigência (Maricato, 2011), mas o dispositivo foi incorporado ao texto constitucional e considerado instrumento básico da política de desenvolvimento e de expansão urbana (Brasil, 1996, Art. 182).

A institucionalização do planejamento urbano coincide com o regime autoritário 1964-1985, quando se sucederam planos estimulados pelo Serfhau, contudo o cenário urbano não foi alterado face ao caráter tecnocrático predominante: seriam atividades "fechadas dentro de si próprias, desvinculadas das políticas públicas e da ação concreta do Estado" (Villaça, 2004, p. 223). Planos diretores serviriam, assim, para regular a ocupação urbana sob a ótica das elites, ocultar conflitos e legitimar o status quo, e por se resumirem a discurso esconderiam o que é recôndito e crucial: a dominação. Por naturalizar as desigualdades socioespaciais, os planos seriam ideológicos, tecnocráticos e apartados da realidade.

Posições menos severas podem ser identificadas em outros autores (Feldman, 2009; Cymbalista, 2007; Rolnik, 2009). Tais percepções mais complacentes reportam-se ao novo marco regulatório da política urbana e à perspectiva de que seus instrumentos urbanísticos e a novidade da conjuntura democrática do país ensejariam um ambiente mais propício aos Planos Diretores Participativos.

Feita essa breve contextualização, analisaremos os processos decisórios desses Planos Diretores, com destaque à incorporação de formatos participativos e seus desenhos institucionais. Metodologicamente, será adotado o modelo proposto por Avritzer (2008), mediante três referenciais analíticos: (i) os termos em que a participação se organiza; (ii) em que medida e com qual alcance o Estado absorve a participação; (iii) qual a influência do marco estritamente institucional. Ainda que as conclusões não sejam idênticas às de seu inspirador, a tipologia adotada permite mensurar o desempenho e o potencial dos desenhos participativos quanto à sua capacidade democratizante e à dependência do sistema político.

Para Avritzer (2008), existiriam basicamente três formatos participativos contemporâneos. 0 primeiro seria um modelo de baixo para cima no qual há livre e ampla participação dos cidadãos (Orçamentos Participativos). 0 segundo seria um desenho de compartilhamento com participação simultânea de representantes estatais e da sociedade civil (Conselhos de Políticas Públicas). 0 último dos desenhos institucionais teria caráter de ratificação, uma vez que as decisões não seriam efetivamente estendidas à sociedade civil, que apenas cumpriria um papel homologatório (Planos Diretores).

Essa abordagem, que não se limita a avaliar determinado desenho institucional como critério absoluto para aferir sua efetividade, permite identificar como as práticas participativas dependem da conduta dos governos, ou ainda verificar as possibilidades de implantação de novos paradigmas de gestão urbana. Diferente do que afirma Avritzer (2008), porém, o Orçamento Participativo e os Conselhos de Políticas Públicas são procedimentos que também se iniciam nas estruturas estatais mediante definição dos parâmetros diversos pelos governos (orçamentários, de políticas substantivas etc.). Igual método se aplica aos Planos Diretores Participativos (PDPs), cujos conteúdos são previamente concebidos nas agências governamentais. As diferenças, portanto, não residem na origem dos formatos participativos.

Embora a literatura registre outros parâmetros mais complexos para defini-las além do calibre populacional, relacionando "funções e, principalmente, o papel que desempenham na rede urbana regional, nacional e internacional" (Castello Branco, 2006, p. 246), aqui será adotada a distinção demográfica do IBGE segundo a qual municípios de porte médio têm população entre 100 mil e 500 mil habitantes.

De outro modo, cidades intermediárias promoveriam a intermediação entre metrópoles/grandes aglomerações e as pequenas cidades/áreas rurais em seus espaços regionais, funcionando "como anteparos e suportes às metrópoles regionais, não compondo junto com estas uma unidade funcional contínua e/ou contígua" (Trindade, 2011, p. 136). Para complementar, a cidade média estaria relacionada ao seu papel regional e ao "potencial de comunicação e articulação proporcionado por suas situações geográficas, tendo no consumo papel mais importante que a produção na estruturação dos fluxos que definem o papel intermediário dessas cidades" (Spósito, 2001, p. 634-5). 
Os municípios estudados são qualificados como centros urbanos com nível de gestão relevante do território (IBGE, 2008), mesmo que tenham diferentes posições hierárquicas regionais ou mesmo distintas bases econômicas: enquanto Piracicaba e Rio Claro têm maior peso do setor industrial, Bauru é predominantemente terciária. ${ }^{6}$ Para além da demografia, estamos autorizados a caracterizá-las como cidades médias em razão de suas características funcionais. Vejamos agora os casos analisados.

\section{Piracicaba}

A elaboração do Plano Diretor transcorreu basicamente na gestão do prefeito José Machado (PT), de 2001 a 2004, tendo sido finalizado por ocasião do II Congresso da Cidade (2004). Com a mudança governamental daquele ano, ocorre uma substantiva alteração processual que culmina com um novo projeto encaminhado pelo novo prefeito, Barjas Negri (PSDB), em dezembro de 2005. Mesmo mantido o escopo geral, a nova legislação ficou bastante comprometida.

Originalmente, o Executivo empreendeu uma metodologia participativa que incluiu levantamento técnico da realidade urbanística, diagnóstico participativo com oficinas de capacitação para lideranças comunitárias (operacionalizado através das redes do Orçamento Participativo) e seminários e entrevistas com representantes de entidades da sociedade civil (universidades, órgãos técnicos de engenheiros e arquitetos). Ao fim, ocorreram dez audiências públicas, duas Conferências e dois Congressos da Cidade. Para tanto, foi contratada a consultoria do Instituto Pólis. 0 conteúdo da Lei n. $186 / 2006^{7}$ é integralmente orientado pelo Estatuto

\footnotetext{
${ }^{6}$ Em Bauru, o peso do setor serviços atinge 78,85\% de seu PIB em 2010 (IPEADATA, 2014). No caso de Piracicaba e Rio Claro, o perfil de polos provedores de serviços de alcance regional lhes confere um caráter especial: também em 2010, os serviços representavam, respectivamente, 57,21\% e $53,88 \%$ de seus PIBs.

7 A íntegra da lei que institui o Plano Diretor de Piracicaba está acessível em <http://www.ipplap.com.br>. Acesso em: 10 fev. 2014.
}

da Cidade: adoção do princípio da função social da propriedade e gestão participativa. ${ }^{8}$

A participação societária nesse processo teve um caráter reativo: as entidades representativas reagiram às convocações governamentais, tomando parte nas audiências públicas, congressos, conferências e outros espaços sempre de forma plebiscitária, basicamente homologando as proposições governamentais. $\mathrm{Ou}$ seja, o controle da agenda sempre pertenceu ao governo, tanto no se refere aos termos com que a participação se daria (as formas de se integrar ao processo participativo) quanto nas questões substantivas (os conteúdos da nova legislação). Exemplos emblemáticos: (i) o formato participativo foi decidido previamente pela equipe de governo, sem que houvesse questionamento ao caráter consultivo dessas iniciativas, pelo contrário, não há registro de contestação; (ii) a metodologia adotada (macrozoneamento que considerou duas variáveis centrais: capacidade de oferta de infraestrutura urbana e preservação/comprometimento ambiental) e o conteúdo da proposta do novo plano também não foram questionados.

Quanto aos critérios metodológicos de análise, o primeiro deles (os termos com que a sociedade se organiza) revela uma evidente impotência da representação civil, pois esta não só não conseguiu se articular em torno de suas reivindicações como jamais assumiu um papel protagonista, resumindose a uma posição coadjuvante de ratificação de propostas originárias do governo local. Notável que assim tenha acontecido, inclusive em uma gestão petista, pois no passado recente alguns movimentos sociais de moradia (mutuários e, sobretudo, favelados) haviam protagonizado importantes mobilizações em defesa da habitação social. De outra parte, nem mesmo entidades de classe ou do mercado imobiliário tiveram protagonismo, resumindo-se a negociar aspectos pontuais do plano proposto. Tais constatações não significam que a sociedade civil fosse ausente, porém demonstra sua inércia e desmobilização, fraqueza que obviamente se refletirá no alcance com que o Estado absorve a participação e define políticas públicas.

Sintomas dessa debilidade e mesmo do despreparo das instituições civis podem ser observados no

\footnotetext{
8 Para uma verificação detalhada desse processo, ver Goulart (2008); para uma análise do debate público através da imprensa local, ver Bologna (2013).
} 
comportamento da imprensa local. Estudo de Bologna (2013) revela que o Jornal de Piracicaba (principal diário local e de orientação editorial conservadora) invariavelmente adotou as posições do governo de turno nas matérias sobre o Plano Diretor, mesmo que houvesse diferenças significativas entre as posições adotadas pelos governos do PT e do PSDB. Ainda que o "PDD tenha sido completamente desfigurado depois de 18 alterações", que a "intenção de ocupar os vazios urbanos tenha ficado inócua devido às sequenciais alterações de perímetro" e que "o macrozoneamento tenha virado figura de retórica", "[os jornais diários] se filiaram ao discurso oficial, ou seja, quando as alterações começaram a acontecer e o discurso oficial dizia que as alterações permitiriam investimentos" (Bologna, 2013, p. 158).

No caso da mídia, a adoção estrita de fontes oficiais, o despreparo profissional na cobertura e a dificuldade em compreender a legislação urbana conduziram a um "alinhamento político com o poder de plantão" (Bologna, 2013, p. 160). Mas a análise pode ser estendida à sociedade civil: nem as associações de favelados e mutuários e tampouco entidades de classe (arquitetos, engenheiros, corretores de imóveis) ou ainda representantes de universidades e organizações não governamentais ligadas a temas urbanos sociais ou ambientais tiveram presença ativa ou formularam propostas. Pelo contrário, aceitaram a primeira versão do governo petista e acolheram, também passivamente, as mudanças do governo tucano que descaracterizaram a proposta original.

A mudança governamental implicou alterações significativas. Embora a proposta original mantivesse a limitação do perímetro urbano, o novo governo promoveu ampliação da ordem de 1/3 do território, ação de largo impacto urbanístico. Além disso, modificou a legislação urbanística (Lei Complementar n. 175 , de $2 / 8 / 2005^{9}$ ), induzindo adensamento de área que colide com o macrozoneamento original (espaço de restrição por limitações de infraestrutura e comprometimento ambiental). Ademais, mudanças dos instrumentos urbanísticos tornaram-nos mais permissivos, reorientação que contrariou o macrozoneamento e as deliberações pactuadas no II Congresso da Cidade. Outra alteração marcante incide sobre a Outorga Onerosa do Direito de Construir:

\footnotetext{
9 Esta etoda a legislação urbanística de Piracicaba aqui referida são acessíveis em <http://www.ipplap.com.br>. Acesso em: 11 fev. 2014.
}

além da ampliação do Coeficiente de Aproveitamento Básico na Zona de Adensamento Prioritário (de 3 para 4), a nova proposta simplesmente faz desaparecer o Coeficiente de Aproveitamento Máximo nas demais zonas urbanas, tornando o instrumento inócuo na prática.

Também digna de nota a simplicidade com que o Executivo usou sua maioria parlamentar para aprovar o Plano Diretor no Legislativo e implantar ações que o contrariavam, seja pela falta de regulamentação (muitos dos instrumentos não são autoaplicáveis), seja pela adoção de medidas de orientação oposta. Como a composição do Conselho da Cidade é controlada pelo Executivo, nem este foro se pronunciou, em evidente manifestação de impotência da sociedade civil.

\section{Bauru}

O processo do Plano Diretor Participativo transcorreu na gestão do prefeito Tuga Angerami (PDT), de 2005 a 2008, e teve início com a montagem do Grupo de Trabalho (de composição mista entre representantes do governo e da sociedade civil) e posteriormente do Grupo de Apoio (equipe de suporte administrativo). Além desses, o Núcleo Gestor (integrado por gestores políticos e técnicos) assumiu a efetiva condução do processo.

0 processo foi desenvolvido em quatro etapas. ${ }^{10}$ A primeira, de Sensibilização, teve duas reuniões em cada setor, orientadas pela metodologia aplicada nos bairros de Tibiriçá e Barra Grande, utilizando exposição através de imagens e explanações sobre o crescimento da cidade e os consequentes impactos urbanísticos para entender a importância do planejamento na organização espacial da cidade.

A segunda etapa, Leitura Comunitária e Leitura Técnica, teve visitas in loco acompanhadas de líderes comunitários para realçar os problemas locais. $\mathrm{Na}$ área rural, foi realizado um tour com integrantes do Grupo de Trabalho e do Núcleo Gestor para conhecer os problemas apontados e realizada Audiência Pública com a comunidade rural para apresentar o diagnóstico geral e as primeiras propostas.

\footnotetext{
${ }^{10}$ A descrição das etapas nos quatro parágrafos que se seguem se vale da pesquisa de López (2013).
} 
Na terceira etapa foram realizados novos encontros com os setores rurais e urbanos, apresentadas as propostas relativas à mobilidade, meio ambiente, habitação, função social das propriedades, etc., quando foram eleitos os delegados para o congresso.

A quarta e última etapa consistiu no Congresso Final, que reuniu os delegados eleitos para análise da minuta do Projeto de Lei do Plano, elaborado por técnicos da Prefeitura. Essa etapa foi realizada em dois dias (27/5 e 3/6/2006) em razão da metodologia didática adotada, qual seja, leitura detalhada de todos os itens, para os quais os delegados podiam fazer destaques com emendas modificativas. Depois a minuta voltou ao prefeito, tendo sido ratificada pelos delegados no dia 16/9/2006.

0 processo foi concluído em 2008, quando o Legislativo aprovou a proposta do Executivo e ganhou a forma de Lei n. 5.631/2008. ${ }^{11}$ A participação contabilizou "114 reuniões contando com a presença de aproximadamente 4.800 pessoas, alcançando média de 42 pessoas por evento" (Ferreira, 2007, p. 23). Critérios quantitativos de participantes podem não representar obrigatoriamente um aprimoramento democrático pela eventual ignorância dos participantes em relação à agenda em debate ou pelo ativismo intenso de minorias que podem subverter os interesses da maioria, mas a participação foi inequivocamente expressiva.

O Plano Diretor também incluiu um item dedicado aos "instrumentos de democratização da gestão", no qual são previstos dispositivos como conferências, assembleias, audiências públicas, plenárias, além de outra originalidade, a saber, a iniciativa popular legislativa de projetos, planos e programas. Os princípios do fomento à participação popular e à capacitação estão inscritos no Art. 285 da Lei do Plano Diretor Participativo, que trata de "efetivar a participação na gestão pública vivência democrática na cidade".

A participação não foi nada desprezível se se considerar a tradição tecnocrática com que o planejamento urbano foi tratado no país (Caldeira \& Holston, 2004) ou mesmo no plano local. A oportunidade de formulação de propostas pelos representantes da sociedade civil se deu basicamente no Congresso da Cidade, no entanto, a liturgia de

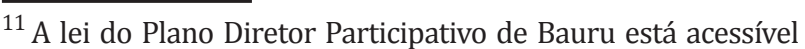
em <http://hotsite.bauru.sp.gov.br/planodiretor/lei.aspx>. Acesso em: 10 fev. 2014
}

leitura e votação de item a item não suprime o fato de que a proposta foi preparada pelo Executivo, com raras alterações. Também neste caso, o governo manteve amplo controle sobre o processo e vale destacar a terceira variável metodológica da pesquisa: se é verdade que o marco institucional tem influência no sentido de compelir os governos a promoverem a participação, no caso empírico o governo foi além da formalidade ao insistir em mecanismos participativos, ainda que mantivesse o controle dos conteúdos das políticas públicas.

A tramitação do projeto teve, finalmente, uma fase derradeira na Câmara Municipal que durou 23 meses, período no qual os atores fundamentais nas negociações foram os representantes do Executivo e do Legislativo, cabendo papel secundário aos representantes civis. Em resumo: "apesar de incorporados vários instrumentos (Macrozoneamento, Zonas Especiais de Interesse Social, Outorga Onerosa, IPTU Progressivo, Direito de Preempção e Estudo de Impacto de Vizinhança etc.), até o presente momento apenas as ZEIS foram regulamentadas pela Lei n. 5.766/2009" (López, 2013 , p. 48). Quanto ao capítulo que trata da participação, é notável que o Conselho do Município só tenha sido regulamentado e implantado em 2013, cinco anos após a promulgação da lei do Plano Diretor.

\section{Rio Claro}

Em meio ao processo nacional de revisão e elaboração de Planos Diretores Participativos, promovido pelo Ministério das Cidades, foi elaborado o Plano de Rio Claro (Lei n. 3.806/2007 ${ }^{12}$ ) na gestão do prefeito Dermeval Nevoeiro Jr. (PFL/DEM), de 2005 a 2008.

Formulado de forma pouco participativa, com algumas reuniões públicas voltadas a públicos restritos ligados a Conselhos Municipais e a entidades técnicas, o plano prevê a "participação das entidades comunitárias no estudo, encaminhamento e solução dos problemas, planos e projetos que lhes sejam concernentes" (Art. $3^{\text {o }}$ da Lei n. 3.806/2007) e um Sistema de Planejamento e Gestão com

\footnotetext{
${ }^{12}$ A íntegra da lei do Plano Diretor de Rio Claro está disponível em <http://www.rioclaro.sp.gov.br/pd/arquivos/Lein3806-2007. pdf>. Acesso em: 15 fev. 2014.
} 
funcionamento de "Conselhos Municipais criados em lei" (Conselho Municipal de Defesa do Patrimônio Histórico; Conselho Municipal de Cultura; Conselho Municipal de Segurança e Defesa Social; todos previstos no Art. 203 da Lei n. 3.806/2007). Além desses, foi instituído o Conselho de Desenvolvimento Urbano (CDU).

Esse processo foi conduzido pela equipe técnica da Secretaria Municipal de Planejamento, Desenvolvimento e Meio Ambiente (Sepladema), com assessoria do Laboratório de Planejamento Municipal (LPM) do Instituto de Geociências e Ciências Exatas da Universidade Estadual Paulista (Unesp). Para tanto, foi criado um Grupo Gestor com a participação de 34 órgãos públicos e entidades civis, dentre os quais dirigentes e técnicos de secretarias, departamentos e autarquias vinculados ao governo local, além de representantes da Ordem dos Advogados do Brasil (OAB), do Conselho Regional de Corretores de Imóveis/Associação dos Corretores de Imóveis de Rio Claro (CRECI/Associrc), dentre outros. A esse grupo coube a organização de um fórum de debates para discutir e encaminhar propostas. Além disso, também foi constituído um Grupo Executivo formado por dirigentes e técnicos da Prefeitura (majoritariamente da Sepladema, com assessoria do LPM/Unesp) e de outros órgãos públicos para sistematizar o novo arcabouço urbanístico.

Foram realizadas algumas reuniões e audiências públicas que contaram com a participação da população e de entidades civis. 0 processo incluiu reuniões com profissionais da área técnica, debates com a participação da população, chegando finalmente à sua aprovação. Essa revisão do plano em 2007 abriu a possibilidade de inserção de alguns instrumentos previstos no Estatuto da Cidade, tais como: parcelamento, edificação ou utilização compulsórios; desapropriação com pagamento em títulos da dívida pública; direito de preempção; operações urbanas consorciadas; transferência do direito de construir; estudo de impacto de vizinhança. Não obstante, o novo plano registra grandes lacunas que obstaculizaram sua aplicação, uma vez que a legislação complementar elaborada não foi levada adiante e tampouco foram regulamentados os instrumentos contidos na lei. ${ }^{13}$

\footnotetext{
$\overline{13}$ Além de nenhum instrumento ter sido regulamentado, dentre as propostas "engavetadas" merecem destaque: Projeto de Lei n. 072/08, sobre Parcelamento do Solo para Fins Urbanos
}

Precisamente em razão de vários conflitos relativos à sua forma de elaboração (pouca abertura à participação popular), ao seu conteúdo (não ter incorporado todos os instrumentos previstos no Estatuto da Cidade e ser incompleto face à importância e incidência da legislação complementar) e à mudança governamental (em 2008 foi eleito um novo prefeito: Du Altimari, do PMDB), o Plano Diretor de 2007 teve sua revisão proposta e aprovada pelos participantes da 3 ${ }^{\underline{a}}$ Conferência da Cidade de Rio Claro, realizada em janeiro de 2010. No mesmo ano a Sepladema solicitou pareceres técnicos de modo a orientar a revisão.

Com base nesse parecer, o governo solicitou ao CDU a revisão do Plano Diretor, com o objetivo de adequá-lo aos princípios do Estatuto da Cidade. Assim, CDU e Sepladema deram início à nova revisão do Plano Diretor ao longo do ano de 2011. Esse processo, que culminou com a apresentação de uma nova versão em meados de 2012, transcorreu mediante uma série de reuniões - tanto nos Conselhos Municipais quanto em alguns bairros da cidade - e três audiências públicas.

Paralelamente, as leis de Parcelamento do Solo e do Zoneamento Urbano também passaram por revisão, promovendo significativa modificação na legislação urbanística. 0 processo, contudo, ainda não foi concluído porque o Executivo não encaminhou o correspondente projeto de lei ao Legislativo.

A revisão do Plano Diretor de Rio Claro teve dois momentos: no primeiro (2007), a participação social foi frouxa (reduzida à interlocução com algumas entidades) e o conteúdo da legislação se notabilizou pela debilidade institucional (outorga onerosa não foi incluída, por exemplo); no segundo (2011 em diante), houve um esforço maior de mobilização social, porém o governo local não encaminhou a proposta de revisão ao Legislativo,

no Município de Rio Claro; Projeto de Lei n. 135/08, sobre Perímetros Urbanos da sede do Município e dos Distritos de Ajapi e Assistência, além das Áreas Urbanas Isoladas de Batovi, Ferraz, e Fontes e Bosques Alam Grei; Projeto de Lei n. 136/08, sobre Unidades Regionais de Planejamento e as Subunidades Regionais de Planejamento, da zona urbana do Município de Rio Claro; Projeto de Lei n. 138/08, sobre o Código de Obras e Edificações do Município; Projeto de Lei n. 139/08, sobre a Lei Municipal de Meio Ambiente; Projeto de Lei n. 140/08, sobre a Política Municipal de Recursos Hídricos; Projeto de Lei n. 142/08, sobre o Zoneamento, Uso e Ocupação do Solo (Ribeirão, 2012, p. 3). 
de modo que, na prática, vigora a legislação ineficaz aprovada em 2007. A conjunção de baixa organização societária e rasa absorção participativa pelo Estado (mesmo em governos de diferentes orientações partidárias e ideológicas: primeiro PFL/ DEM e depois PMDB) tornou o marco institucional igualmente inexpressivo, ou seja, a exigência de processos participativos fez com que a influência do marco institucional se tornasse meramente litúrgica.

\section{Considerações finais}

Os dados permitem inferir características comuns às três cidades quanto à limitação da experiência participativa de elaboração de seus novos Planos Diretores. Essa constatação contraria as expectativas que se forjaram ao longo da transição brasileira de que a participação seria automaticamente mais democrática porque atenuaria o peso político das elites governantes e suficiente para promover distribuição de bens e serviços. Tal crença, de um lado, subestimou o processo de institucionalização dos mecanismos participativos e, de outro, superestimou os termos em que a "participação se organiza".

Os primeiros itens de análise (como a participação se organiza e com qual alcance o Estado absorve a participação) não podem ser tratados separadamente porque estão imbricados em relação de interdependência. A hipótese explicativa é que uma baixa organização da sociedade civil determina proporcional capacidade de absorção participativa pelas instituições estatais. Como não foi registrada uma participação societária mais vigorosa, através de movimentos sociais organizados tematicamente como da habitação, por exemplo, que historicamente foi protagonista da reforma urbana -, e a interlocução se fez basicamente através de entidades comunitárias ou de classe, os governos não tiveram dificuldade em manter controle sobre a agenda e as políticas públicas atinentes. Embora haja variações, a dinâmica participativa dos três casos esteve subordinada aos atores estatais, cujo controle substantivo sobre procedimentos participativos foi efetivamente alto.

Em Bauru, os números foram mais expressivos, a metodologia empregada promoveu grande quantidade de reuniões, assembleias, capacitação e plenárias até chegar a duas sessões congressuais.
Todas essas atividades foram diretamente organizadas e conduzidas pela Prefeitura local, de modo que o Grupo de Trabalho e o Núcleo Gestor definiram os termos da participação e isso implicou a subordinação da participação civil. Nem mesmo a simbólica votação do projeto de lei (artigo por artigo) atenua esse controle, pois coube ao Executivo definir não só o que seria votado como seus conteúdos.

Processo similar ocorreu em Piracicaba, ainda que com números participativos menos expressivos. Da leitura participativa às entrevistas com representantes de entidades, passando pelas audiências públicas até se chegar ao Congresso da Cidade, a equipe do governo local jamais perdeu o controle do conteúdo substantivo e legal do novo Plano Diretor. Da mesma forma como em Bauru, o governo local apresentou e sistematizou o texto da lei.

Em Rio Claro, o processo foi menos intenso em termos participativos. As consultas transcorreram de forma episódica e de tal maneira superficial que está em curso novo processo de revisão que, afora a não incorporação de todos os instrumentos do Estatuto da Cidade, identificou a baixa participação como um dos motivos principais.

Forte peso do governo e fragilidade da sociedade civil ensejam os termos em que a participação efetivamente transcorreu. Isso não significa que o formato não seja necessariamente democratizante, apenas expõe seus limites mediante análise empírica. Há uma grande dependência do sistema político e pesa também a orientação político-ideológica do governo de turno, evidenciando o caráter acentuadamente homologatório desse tipo de processo participativo na medida em que se limita a ratificar políticas públicas formuladas ex ante pelos atores estatais.

A propósito, uma primeira avaliação das experiências recentes de planejamento urbano com base em Planos Diretores Participativos no país revela o mesmo cenário: "a maioria dos Conselhos das Cidades tem caráter consultivo" ou "necessita ser regulamentada, ou seja, também nesse caso o Plano Diretor não é autoaplicável" (Santos \& Montandon, 2011, p. 46). Mais ainda, "os instrumentos ou não são autoaplicáveis ou são remetidos à regulamentação posterior, ficando à mercê de sujeições político-institucionais e de interesses particulares, comprometendo sua eficácia" (Goulart et al., 2014, s.p.). 
Outro aspecto a observar é o conteúdo discursivo do que a literatura chama difusamente de participação. No sentido literal - de que se criaram espaços para atores civis tomarem parte do processo - a definição pode ser admitida, no entanto os formatos participativos foram representativos. Representantes se fizeram de representados, inclusive votando (casos dos congressos em Piracicaba e Bauru). A participação de que se trata não só não foi massiva como se deu à base de delegação e transferência de aspirações e interesses - ingredientes clássicos que definem a representação. ${ }^{14} \mathrm{~A}$ confusão semântica não pode ignorar que, a rigor, observamos processos participativos de representação que consistem em alargar os espaços nos quais são debatidas políticas de interesse público, em que pese seu caráter efetivamente ratificador.

A despeito da relativa demora da tramitação do projeto no Legislativo em Bauru, da retirada para modificações em Piracicaba em razão da mudança governamental e do formalismo observado em Rio Claro, em todos os casos o Executivo aprovou com facilidade seus projetos. Isso revela tanto a fraqueza e o despreparo do Legislativo para temas complexos como a legislação urbanística quanto o amplo controle exercido pelo Executivo nos processos decisórios. Vale lembrar: o Executivo tem o monopólio da iniciativa em matérias legislativas fundamentais (orçamento, legislação urbanística etc.), daí que o extenso poder de agenda que se verifica na esfera federal (Limongi, 2006) também se reproduz no plano municipal.

Por último, a questão envolvendo a forma como está disposta a legislação e a influência do marco institucional. 0 Estatuto da Cidade impõe a obrigatoriedade do Plano Diretor e a participação, com sanções caso essas exigências não sejam cumpridas. Portanto, a agenda é claramente uma imposição institucional. Não obstante a obrigatoriedade do desenho institucional, como as regras do jogo são genéricas, os formatos adotados variam conforme as predileções do governo de turno. Os limites da participação em Piracicaba e Bauru e a forma litúrgica com que foi conduzida em Rio Claro revelam nitidamente que a efetividade do formato

\footnotetext{
${ }^{14}$ Subversão conceitual similar se faz nas análises sobre o Orçamento Participativo (Miguel, 2005).
}

institucional depende de como o Executivo implanta a participação.

A dependência do sistema político é baixa no que concerne à obrigatoriedade do desenho (exigência do plano e da participação), mas bastante alta em termos objetivos: os dispositivos através dos quais a participação é concretizada não só variam como podem ser mais ou menos efetivos. Embora as instituições contem no cômputo geral, a política faz (enorme) diferença.

Tais deduções são empiricamente demonstradas pela análise comparada, que, apesar de nuanças e variações, revela características comuns aos três processos, especialmente o baixo grau de organização participativa da sociedade e a consequente modesta absorção de suas demandas. 0 marco institucional exige a participação, mas esta é realizada conforme as preferências do governo de turno, logo é uma variável frouxa.

Como as escolhas político-ideológicas são relevantes, não se pode ignorar que a escala esquerdadireita pode ser um critério valioso nas explicações das condutas governamentais. As mudanças dos governos que se sucederam em Piracicaba, a maior inclinação à participação em Bauru e a conduta oposta em Rio Claro evidenciam que governos situados à esquerda de espectro ideológico são mais propensos a desenhos democratizantes. Evidente que as regras contam, mas a condução política é crucial na implantação de Planos Diretores Participativos (Goulart, 2008).

Em que pesem os limites constatados, o modelo de Plano Diretor Participativo preconizado pelo Estatuto da Cidade representa um avanço em relação à tradição de planos tecnocráticos, tanto pela exigência da participação quanto pela disponibilidade de instrumentos urbanísticos orientados para a função social da cidade.

A inovação reside em práticas democráticas à medida que promovem o alargamento da cidadania, particularmente do direito de participar de decisões públicas, mesmo que estas (ainda) permaneçam sob o controle dos atores estatais. A virtude de desenhos institucionais como os Planos Diretores Participativos não diz respeito à efetiva capacidade decisória compartilhada com representantes da sociedade civil - com efeito, modesta -, mas em seu significado simbólico e no seu caráter pedagógico e inclusivo. Para aferir o desempenho da democracia, 
"o certo é procurar perceber se aumentou não o número dos que têm direito de participar das decisões que lhes dizem respeito, mas os espaços nos quais podem exercer esse direito" (Bobbio, 1986, p. 28). Nesse sentido, a participação é valiosa, não obstante suas limitações.

Mesmo homologatória - no sentido de que teve baixa incidência sobre as decisões governamentais -, a participação se inscreve em um movimento amplo de democratização dos processos decisórios de políticas públicas que ensejam a possibilidade de mecanismos mais democráticos na gestão urbana (conselhos, conferências etc.). Um exame crítico da participação pode atenuar as expectativas mais otimistas que se forjaram nos últimos tempos, mas também serve para identificar seus limites em perspectiva aperfeiçoadora.

\section{Referências}

Avritzer, L. (2008). Instituições participativas e desenho institucional: algumas considerações sobre a variação da participação no Brasil democrático. Opinião Pública, 14(1), 43-64. http://dx.doi.org/10.1590/ S0104-62762008000100002.

Bobbio, N. (1986). O futuro da democracia: uma defesa das regras do jogo. Rio de Janeiro: Paz e Terra.

Bologna, S. R. (2013). A imprensa local e a função social da cidade - análise de notícias sobre as alterações no Plano Diretor de Desenvolvimento de Piracicaba (SP) (Trabalho de Conclusão de Curso). Programa de Pós-Graduação em Comunicação Jornalística, Pontifícia Universidade Católica de São Paulo, São Paulo.

Brasil (1996). Constituição da República Federativa do Brasil de 1998. Brasília: Diário Oficial da União.

Brasil (2002). Estatuto da Cidade: guia para Implementação pelos Municípios e Cidadãos: Lei n. 10.257, de 10 de julho de 2001, que estabelece diretrizes gerais da política urbana (2a ed.). Brasília: Câmara dos Deputados.

Caldeira, T. P., \& Holston, J. (2004). Estado e espaço urbano no Brasil: do planejamento modernista às intervenções democráticas. In: L. Avritzer (Org.). A Participação em São Paulo. São Paulo: Ed. UNESP.
Castello Branco, M. L. (2006). Cidades médias no Brasil. In: E. S. Spósito, M. E. B. Spósito, \& O. Sobarzo (Orgs.). Cidades médias: produção do espaço. São Paulo: Expressão Popular. Cymbalista, R. (2007). Instrumentos de planejamento e gestão política urbana: um bom momento para uma avaliação. In: L. M. M. Bueno, \& R. Cymbalista (Orgs.). Planos Diretores: novos conceitos de planejamento territorial. São Paulo: Annablume.

Doimo, A. M. (1995). A vez e a voz do Popular: movimentos sociais e participação política no Brasil pós 70 . Rio de Janeiro: Relume-Dumará/ANPOCS.

Feldman, S. (2009). Constituição de 1988 e política urbana no Brasil: recuperando um percurso de construção de ideias e práticas. In: J. O. Goulart (Org.). As múltiplas faces da Constituição cidadã. São Paulo: Cultura Acadêmica.

Ferreira, R. D. (2007). Os descaminhos do Plano Diretor: da sensibilização à insensibilidade (Monografia de Conclusão de Curso). Faculdade de Arquitetura, Artes e Comunicação, Universidade Estadual Paulista "Júlio de Mesquita Filho", Bauru.

Goulart, J. O. (2008). Estatuto da Cidade e Plano Diretor Participativo: instituições contam e a política faz diferença. Cadernos IPPUR, XXII(1).

Goulart, J. O., Terci, E. T., \& Otero, E. V. (2014). Planos Diretores Participativos e gestão urbana em cidades médias do interior paulista sob o Estatuto da Cidade. Biblio 3W - Revista Bibliográfica de Geografía y Ciencias Sociales, XIX. Recuperado em dia de março de 2014, de http://www.ub.edu/geocrit/bw-ig.htm.

Habermas, J. (1990). Soberania Popular como Procedimento. Novos Estudos, (26), 100-113.

Habermas, J. (1997). Direito e democracia: entre factividade e validade (Vol. II). Rio de Janeiro: Tempo Brasileiro.

Instituto Brasileiro de Geografia e Estatística - IBGE (2008). Regiões de Influência das Cidades. Rio de Janeiro: IBGE.

IPEADATA (2014). Base de Dados - Macroeconômico, Regional e Social. Recuperado em dia de março de 2014, de http://www.ipeadata.gov.br/.

Kowarick, L. (1993). A espoliação urbana (2a ed.). Rio de Janeiro: Paz e Terra.

Kowarick, L. (2000). Escritos Urbanos. São Paulo: Ed. 34. 
Lavalle, A. G. (2011). Após a Participação: nota introdutória. Lua Nova, 84, 13-23.

Lavalle, A. G., \& Vera, E. I. (2011). A trama da crítica democrática: da participação à representação e à accountability. Lua Nova, 84, 95-139.

Limongi, F. P. (2006). A democracia no Brasil. (Novos Estudos, n. 76). São Paulo: CEBRAP.

López, G. R. (2013). O processo participativo do Plano Diretor de Bauru (Relatório Final de Pesquisa de Iniciação Científica). Faculdade de Arquitetura, Artes e Comunicação, UNESP, Bauru.

Maricato, E. T. (1987). Política Habitacional no Regime Militar: do milagre brasileiro à crise econômica. Petrópolis: Vozes.

Maricato, E. T. (2011). O impasse da política urbana no Brasil. Petrópolis: Vozes.

Maricato, E. T. (2000). As idéias fora do lugar e o lugar fora das idéias: Planejamento Urbano no Brasil. In: O. Arantes, C. Vainer, \& E. T. Maricato (Eds.). A cidade do pensamento único: desmanchando consensos. Petrópolis: Vozes.

Miguel, L. F. (2005). Teoria da democracia atual: esboço de mapeamento. BIB - Revista Brasileira de informação bibliográfica em ciências sociais, 59.

Michiles, C., Whitaker, F., Coelho, J. G. L., Vieira Filho, E. G., \& Veiga, M. G. M., \& Prado, R. P. S. (1989). Cidadão constituinte: a saga das emendas populares. Rio de Janeiro: Paz e Terra.

Pateman, C. (1992). Participação e teoria democrática. Rio de Janeiro: Paz e Terra.

Rolnik, R. (2009). Democracia no fio da navalha - limites e possibilidades para a implementação de uma agenda de reforma urbana no Brasil. Revista Brasileira de Estudos Urbanos e Regionais, 11(2).

Ribeirão, C. (2012). O Plano Diretor e a Produção Imobiliária em Rio Claro - 1980-2010 (Relatório de Resultados de
Pesquisa de Iniciação Científica). Escola Superior de Tecnologia e Educação de Rio Claro, Associação de Escolas Reunidas, Rio Claro.

Sader, E. (1988). Quando novos personagens entraram em cena: experiências, falas e lutas dos trabalhadores da Grande São Paulo, 1970-1980. Rio de Janeiro: Paz e Terra.

Santos, O. A. Jr, \& Montandon, D. T. (2011). Os Planos Diretores Municipais pós-estatuto da cidade: balanço crítico e perspectivas. Rio de Janeiro: Letra Capital; Observatório das Cidades; IPPUR/UFRJ.

Schumpeter, J. (1984). Capitalismo, socialismo e democracia. Rio de Janeiro: Zahar.

Spósito, E. S., Spósito, M. E. B., \& Sobarzo, O. (Orgs.) (2006). Cidades médias: produção do espaço. São Paulo: Expressão Popular.

Spósito, M. E. B. (2001). As cidades médias e os contextos econômicos contemporâneos. In: M. E. B. Spósito (Org.). Urbanização e cidades: perspectivas geográficas. Presidente Prudente: FCT/Unesp.

Trindade, S. C. Jr (2011). Cidades Médias na Amazônia Oriental: das Novas Centralidades à Fragmentação do Território. Revista Brasileira de Estudos Urbanos e Regionais, 1-3(2), 135-151.

Valladares, L. P. (1994). Cem anos pensando a pobreza (urbana) no Brasil. In: R. Boschi (Org.). Corporativismo e Desigualdade - a construção do Espaço Público no Brasil. Rio de Janeiro: IUPERJ; Rio Fundo Editora.

Villaça, F. (2004) Uma contribuição para a história do planejamento urbano no Brasil. In: C. Deak, \& S. R. Schiffer (Orgs.). O processo de urbanização do Brasil. São Paulo: Edusp.

Recebido: Mar. 07, 2014

Aprovado: Jul. 01, 2014 